\title{
The good, bad, and the ugly of regenerative therapies for erectile dysfunction
}

\author{
Jeffrey D. Campbell ${ }^{1}$, Uros Milenkovic ${ }^{2}$, Mustafa Faruk Usta ${ }^{3}$, Maarten Albersen ${ }^{2}$, Trinity J. Bivalacqua ${ }^{4}$ \\ ${ }^{1}$ Department of Surgery, Division of Urology, Western University, London, ON, Canada; ${ }^{2}$ Laboratory for Experimental Urology, Department \\ of Development and Regeneration, University of Leuven, Leuven, Belgium; ${ }^{3}$ Department of Urology, Section of Andrology, Akdeniz University \\ School of Medicine, Antalya, Turkey; ${ }^{4}$ The James Buchanan Brady Urological Institute and Department of Urology, The Johns Hopkins School of \\ Medicine, Baltimore, Maryland, USA \\ Contributions: (I) Conception and design: JD Campbell, TJ Bivalacqua; (II) Administrative support: None; (III) Provision of study material or patients: \\ N/A; (IV) Collection and assembly of data: JD Campbell, U Milenkovic, MF Usta; (V) Data analysis and interpretation: JD Campbell, U Milenkovic, \\ MF Usta; (VI) Manuscript writing: All authors; (VII) Final approval of manuscript: All authors. \\ Correspondence to: Jeffrey D. Campbell. Department of Surgery, Division of Urology, Western University, London, ON, Canada. \\ Email: jcampb49@uwo.ca.
}

\begin{abstract}
Erectile dysfunction (ED) is a common condition which reduces quality of life of both patients and their partners, and is a significant health care expense every year. Although phosphodiesterase type5 inhibitors are the current first-line treatment for men with ED, they are limited by their on-demand dosing, intolerance, and variable efficacy in complex patient populations such as men with multiple medical comorbidities or ED after pelvic surgery. Regenerative medicine has been introduced and investigated in andrology as an encouraging strategy to restore diseased erectile tissue structure and function. Novel regenerative therapies for ED are controversial but are perceived to offer a durable and safe tissue restorative approach to act as a long-term solution to this cumbersome disease process. Here, we review platelet-rich plasma, amniotic fluid membranes, low-intensity extracorporeal shockwave therapy, and stem cell therapy as regenerative strategies to treat ED. Most of these approaches have preclinical and occasionally clinical data to support their ongoing investigation; however, none of these treatments are currently supported for use in ED patients outside of clinical trials.
\end{abstract}

Keywords: Erectile dysfunction (ED); low-intensity extracorporeal shockwave treatment; amniotic fluid; chorion grafts; stem cell therapy; platelet-rich plasma

Submitted Jun 01, 2019. Accepted for publication Oct 04, 2019.

doi: $10.21037 /$ tau.2019.10.06

View this article at: http://dx.doi.org/10.21037/tau.2019.10.06

\section{Introduction}

Erectile dysfunction (ED) affects men and their partners worldwide, and despite advances in its medical clarification and potential therapies, our treatment options and outcomes have been unable to keep pace with the increase of ED prevalence. Approximately 322 million men worldwide are predicted to be diagnosed with ED by 2025 , which is more than double the prevalence measured in 1995 (1). Currently, the prevalence of ED in the general population ranges from $30 \%$ to $65 \%$ in men aged 40 to 80 years (2). ED has a negative impact on both patient and partner quality of life and costs the United States approximately \$330 million annually (3).

In addition to conservative management and lifestyle modifications, men seeking medical treatment for ED are prescribed a phosphodiesterase type 5 inhibitor (PDE5i) as first-line therapy $(4,5)$. In the case of mild-to-moderate $\mathrm{ED}$, these medications have demonstrated strong clinical benefits in randomized controlled trials (RCTs) (6-9). Men with severe ED due to diabetes mellitus, advanced age, and/or after radical prostatectomy (RP) for prostate cancer often have a less robust long-term response to these 
on-demand medications and typically require additional management strategies (4). More invasive treatments such as intracavernous injections and surgical implantation of a penile prosthesis remain a gold standard treatment for medication refractory ED; however, they are typically less attractive due to the fear of needles, cost, and potential complications or additional side effects $(5,10,11)$.

Novel strategies to treat ED have centered around regenerative therapies, which aim to restore the structure and function of diseased erectile tissue and offer a "cure" to this disease as opposed to a mere treatment of symptoms (12). A truly regenerative model would allow for long-term maintenance of erectile function through downstream regulation of growth factors along with both nerve and muscle cell regeneration. Some of the regenerative approaches for the treatment of ED currently being studied include platelet-rich plasma (PRP), amniotic fluid matrices, low-intensity extracorporeal shockwave therapy (LiESWT), and stem cell therapy (SCT) (13). Although a significant amount of preliminary research has been completed exploring the regenerative treatment options for ED, there is a paucity of good quality human data to support their use as a standard therapy in clinical practice (13). The data advocating for or against each technology is controversial, and there remains an important debate on the horizon the core of which is the subject of this review. The Sexual Medicine Society of North America (SMSNA) has issued a consensus statement clarifying that novel technologies, including PRP, LiESWT, and SCT, should only be used under supervision of a rigorously designed clinical trial (14). Despite this recommendation, men's health clinics are becoming increasingly more common and offering these therapies at exorbitant costs to the patient. The following is a review of the controversial literature surrounding the most studied regenerative therapies for ED. Its purpose is to generate discussion about these technologies along with their role in future research, and to provide evidence to support clinical decision making.

\section{Platelet-rich plasma (PRP)}

Platelet-derived therapies have been gaining popularity in many fields of medicine. PRP is autologous blood plasma that contains more than four times normal human physiological serum platelet concentration and is rich in many growth factors (15). The biological molecules active within PRP have been hypothesized to upregulate cell regeneration in a downstream fashion $(16,17)$. As it pertains to ED, PRP has been found to contain growth factors such as vascular endothelial growth factor (VEGF), plateletderived growth factor (PDGF), epidermal growth factor (EGF), insulin-like growth factor (IGF), and fibroblast growth factor (FGF) $(18,19)$. Many of these growth factors have been shown to have a role in improving erectile function in both preclinical and clinical studies (20). Specifically, animal studies injected with VEGF and using a cavernous nerve injury (CNI) model of ED have shown greater salvage of erectile function compared to controls (21). VEGF-induced erectile function recovery appears to be mediated through the endothelial nitric oxide synthase (eNOS) pathway, and this mechanism is the main constituent of a theory explaining how this growth factor in PRP can improve erectile function (22). For example, PRP has shown a regenerative nerve effect in peripheral nerve injury studies and studies using animal models of ED after CNI. This data suggests that there exists a nerve regeneration mechanism to improve erectile function (23-25). In the CNI models, PRP growth factors were injected into the corpora cavernosa at the time of CNI. Four weeks after a single injection, Wu et al., observed a reduction in cell apoptotic markers, reduced fibrosis, and an improvement in erectile function $(24,25)$. This group further experimented with techniques to optimize autologous PRP from humans and tested this in animals, confirming the presence of the previously mentioned growth factors (12). There has been a lack of significant basic science exploring PRP in ED beyond these promising initial studies, which are limited by the low number of animals tested and unconventional penile pressure monitoring.

Phase I-II human trials utilizing PRP for treating ED have been ongoing in Moscow since 2013. A phase I human trial has demonstrated patient safety when using intracavernous injections of PRP for both ED and Peyronie's disease (PD) (17). Ongoing human studies have evaluated the difference between PRP with bioactive molecules versus concentrations with inactivated growth factors. Phase II trials have explored the use of PRP in ED, $\mathrm{PD}$, and stress urinary incontinence (17). Intracavernous injection of PRP was performed in a total of 5 patients with ED. There were no major adverse outcomes in any of the study groups although penile bruising was observed in about $40 \%$ of patients. This study had no placebo comparison, the number of injections varied (median of 2 ), and the amount of injectable PRP varied (2-9 mL), making these results difficult to interpret in regard to treatment efficacy. Importantly, no patients had worse ED, and there was an average improvement in post-treatment IIEF 
score of 4 points, indicating a small, but clinically relevant improvement in these patients (17).

Before this therapy can be applied and studied on a larger scale, researchers within the field of urology/ andrology need to agree on a standardized technique for the isolation and activation of growth factors. Various methods of activation are being employed, which may significantly alter the bioactive molecules in a sample. Different specialties require different activated growth factors, and, in order to organize multi-center RCTs for sexual medicine, a consistent standard should be created. Changing the activation protocol runs the risk of having a poor availability of growth factors, altered patient safety, and inconsistent results (26).

There is a lack of understanding as to whether PRP can play a neuroprotective or nerve regeneration role in salvaging erectile function after CNI, and additional studies comparing early versus delayed administration would be beneficial (20). Currently, the Mayo Clinic (Rochester, MN, USA) is recruiting patients for a clinical trial that involves the application of autologous PRP circumferentially around the neurovascular bundle during a radical prostatectomy as a neuroprotective mechanism (https://clinicaltrials.gov/ct2/ show/NCT02957149) (12).

Overall, the currently available data suggest that PRP treatment for ED is safe, with human studies attesting to a low risk of adverse events. Although this treatment has been successful in other fields of medicine (19,27-29), we cannot conclude that there is a long-term functional benefit in sexual medicine. Based on other medical literature, the clinical utility or PRP is sound, due to the presence of growth factors; however, the current data using PRP for ED has low patient numbers, a lack of controls, and questionable clinical efficacy. Further animal studies are needed to clarify the mechanisms of PRP in erection recovery and a standardized activation protocol, injection regimen, and injection dose/concentration needs to be established by the scientific community. Further prospective and randomized placebo-controlled trials are needed before this treatment can be accepted as a therapy to improve erectile function.

\section{Amniotic fluid matrices}

Despite minimally invasive techniques and nerve regeneration therapies, CNI during RP inevitably results in neuropraxia (20). A novel nerve regeneration strategy has been described that uses dehydrated human amnion/ chorion membranes (dHACM) as a source of implantable neurotrophic factors and cytokines. Enzyme-linked immunosorbent assay (ELISA) analysis of these membranes have found growth factors, cytokines, proteases, and inhibitors of inflammatory and fibrotic pathways (30).

These chorion grafts were initially developed for wound healing in patients with complex injuries and burns, however recently $\mathrm{dHACM}$ have been implemented as a neuroprotective mechanism during RP (31). Patel's group were the first to implement $\mathrm{AHACM}$ as a wrap around the neurovascular bundle during RP. These wraps were utilized for their mechanism of hastening nerve recovery and thus improving erectile function after RP $(32,33)$. A cohort of 58 patients received the dHACM graft and were followed-up for an average of 4 months, and the return to potency was significantly quicker in the DHCAM group (1.34 months) compared to the control group (3.39 months) (32). This early clinical study that was published in 2015 has limited follow-up, low patient numbers, and inadequate controls and therefore cannot itself justify routine usage in the surgical practice. However, a follow-up study increased the study numbers to nearly 250 patients with $\mathrm{dHACM}$ treatment and a satisfactory follow-up period of over a year (33). Similar to the previous study, potency, defined as the ability to achieve an erection adequate for intercourse, was expedited with use of the dHACM compared to controls (2.3 vs. 3.9 months, respectively). Reported potency rates were higher in all of the early recovery stages; however, at 1 year after surgery, these were equivalent and there did not appear to be any long-term benefit (33). This study is a stronger support for chorion grafts as a potential nerve regeneration mechanism to promote early erectile function recovery after RP. Since there was no statistical difference in potency rates one year after surgery, the role of AHACM appears to be primarily for early recovery rather than long-term potency improvement (33).

Randomized controlled clinical trials are underway to further advance this novel technology and, if successful, would offer a rehabilitative approach to improving erectile function earlier after RP and thus could play an important role for improvement in quality of life after cancer survivorship.

\section{Low-intensity extracorporeal shock wave therapy (LiESWT)}

LiESWT is a novel treatment modality for men with ED that has quickly gained popularity based on data from both in vivo and in vitro studies $(34,35)$. Basic sciences studies 
have revealed that LiESWT can stimulate angiogenesis, which acts as a potential mechanism to improve erectile function (36). Multiple different animal models of ED have been explored in order to evaluate the mechanisms of LiESWT on penile tissue (37). These preclinical studies suggest that the beneficial effects perceived by LiESWT on erectile function in $\mathrm{CNI}$ and diabetic animal models are both neuroprotective and nerve regenerative (20,38-40). In animal models, there is consistently an increase in intracavernous pressure following cavernous nerve stimulation and LiESWT compared to control animals $(36,38,41)$. Intracavernous pressure changes correlate clinically with an improvement in erectile function and therefore these studies support the use of LiESWT to improve erectile function. Additionally, LiESWT therapy applied to the corpora cavernosa appears to improve penile blood flow parameters and endothelial function by stimulating angiogenesis $(21,22)$. Post-RP animal models assessing the efficacy of LiESWT have demonstrated increased brain-derived neurotrophic factor (BDNF) expression, angiogenesis through VEGF activation, and recruitment of endogenous progenitor and Schwann cells $(40,42)$. Combination therapy of mesenchymal stem cell therapy (MSCT) in conjunction with LiESWT in a diabetic rat model has been reported (43). In addition, the therapeutic efficacy of human adipose-derived stem cells (h-ADSCs) applied to CNI animal models of ED in combination with LIESWT to the corpora cavernosa has demonstrated a potentiated improvement in erectile function (44).

There have been limited, well-designed prospective and randomized clinical studies evaluating LiESWT for isolated ED (45-49). There have also been human trials exploring the use of LiESWT for PD and pelvic pain syndromes; however, these have shown mixed results and will not be discussed here $(50,51)$. Unfortunately, the quality of the available data is poor, there is no agreed upon treatment protocol, and longterm benefits are questionable at best (52-56).

The original study that evaluated the safety and efficacy of LiESWT in ED was a single-arm trial that enrolled 20 patients with vasculogenic ED in 2010 (57). This study included men with mild-to-moderate vasculogenic ED who failed to respond to PDE5I therapy. Erectile function was improved in 15 of the 20 men and the mean increase in International Index of Erectile Function - Erectile Function Domain (IIEF-EF) score was 7.4 at 3-month follow-up. Additionally, nocturnal penile tumescence parameters improved in the 15 men who responded to LiESWT treatment (57).

In a similar study by Vardi et al., short-term results of a randomized, double-blinded, sham controlled study were reported and LiESWT was observed to have a positive short-term clinical and physiological effect on erectile function in men who responded to oral PDE5I therapy (46). Additionally, LiESWT therapy was shown to be effective in improving erectile function in men with severe ED who were also PDE5I non-responders. About half of the patients in this trial were able to have satisfactory sexual intercourse with the use of PDE5Is after LiESWT treatment (49). Similarly, Tsai et al. found that $94.3 \%$ of patients who responded to LiESWT had durable treatment responses at 3-month follow-up, suggesting that LiESWT may be a salvage therapy for ED patients who fail to respond to PDE5I's (58). Finally, another study noted that, although LiESWT seems to an effective treatment option in men with $\mathrm{ED}$, age and co-morbidities are negative predictive factors of therapeutic success (59).

In contrast, a double-blind RCT by Fojecki et al. investigated the effectiveness of LiESWT in 126 men with ED of different etiologies and reported no clinically significant effect on erectile function (60). In addition, Fojecki et al. also demonstrated that 2 cycles of LiESWT for ED were not superior to 1 cycle at both 6- and 12-month follow-up (61). Another prospective, doubleblinded RCT involving 105 men with ED of different etiologies did not find a statistically significant difference in erectile function between the LiESWT study group and the placebo group (62). There have also been mixed results reported regarding the efficacy of LiESWT treatment on penile Doppler ultrasonography parameters $(48,63)$.

There are five systematic reviews and meta-analyses assessing the efficacy of LiESWT for treatment of ED (52-56). Only one of these meta-analyses strictly evaluated RCTs studying the treatment of ED with LiESWT and limited the confounding factors such as alternate study designs and inclusion criteria other than ED (52). A total of 7 RCTs were evaluated and, although there was significant heterogeneity between the setup parameters, device specifications, and treatment protocols, the studies concluded that there was a clinical improvement with LiESWT, and importantly no significant adverse events. This observation supports the importance of developing standardized treatment protocols for each shockwave machine and exploring clinical trials with longer followup periods (52). Additionally, four other meta-analyses and systematic reviews supported the finding that the treatment 
of ED with LiESWT ultimately results in a significant increase in IIEF-EF score and erection hardness score (EHS) (53-56). These meta-analyses include several RCTs with significant limitations, including high dropout rates and limited statistical analysis. In summary, the efficacy and more importantly, the duration of efficacy of LiESWT treatment for men with ED remains undefined. In summary, the heterogeneity of treatment parameters (dosing frequency, energy flux density settings, number of shocks, linear $v s$. focused shockwave device) used in each study also makes comparison and interpretation difficult.

The FDA has not approved LiESWT devices for the treatment of ED in the United States. RCTs with a high number of patients and long-term (2-4 years) follow-up using a validated and standardized protocol need to be conducted before this modality can be routinely used in men with ED. In 2017, the Sexual Medicine Society of North America released a position statement regarding restorative therapies for ED urging the medical and scientific community to continue to better understand the mechanisms and clinical benefit of LiESWT before adding this modality to the ED therapy armamentarium (14).

\section{Stem cell therapy (SCT)}

The potential of regenerative medicine and stem cells, in particular, lies in the fact that "cure" is ranked the highest when patients are asked to define the success of outcome variables (64). Stem cells possess regenerative capacities through both pleiotropic and paracrine effects. Currently, the most frequently used and readily available source of stem cells are mesenchymal stem cells (MSCs) (65). In contrast to embryonal-derived stem cells, they have little tumorigenic potential and no ethical constraints (66). They were initially described as a fibroblast-like population of cells derived from bone marrow (67), but they were subsequently isolated from a myriad of tissues such as muscle tissue, brain tissue, fallopian tubes, ligaments, synovium, and adipose tissue (68). It has been shown in many preclinical in vitro or in vivo studies that these cells promote cell growth (trophic effects), survival and proliferation, neo-vascularization, re-epithelialization, and immunomodulation through the release of a complex concoction of cytokines (69). A significant advantage of MSCs includes the fact that allogenic therapeutic administration is possible without usage of immunosuppressive mediation (70). While allogenic MSCs are not "immune privileged" (i.e., they cannot escape the host immune system entirely), they can however evade the immune system by creating an immunomodulatory milieu through suppression of antigenpresenting cell maturation and $\mathrm{T}$ cell activation (71). Moreover, in their undifferentiated state, MSCs produce very little major histocompatibility complex (MHC) class I and lack MHC class II expression, further adding to their minimally immunogenic properties (72). This allows for use of either allogenic or autogenic stem cells in the clinical setting (73).

Until the past decade, MSCs were thought to elicit their regenerative effect through multipotent cell division and restoration of resident damaged, apoptotic, or necrotic cells $(74,75)$. However, more recent investigations have revealed that stem cells do not "replace" parenchymal cells, but function as an on-site drug store releasing many growth factors, cytokines, and chemokines in a paracrine fashion that promote wound healing and decrease inflammation (76). Recently, there has been a rise in interest for the potential of stem-cell-cultured media (secretome) (77). This biofactor (growth factors, cytokines, and chemokines)rich cultured medium could prove to have significant therapeutic potential. Lee et al. (78) examined the wound healing properties of endothelial precursor cells. It was determined that after either topical or injection treatment they improved wound healing significantly by secretion of epidermal growth factor, fibroblast growth factor, granulocyte-macrophage colony-stimulating factor, interleukins, platelet-derived growth factor, and VEGF (78).

There have been a limited number of clinical trials investigating the role of stem cells for sexual dysfunction indications (post-RP ED, diabetic/vascular ED, and PD-related ED and fibrosis) (79-86). Yiou et al. (79) administered escalating doses of MSC in a phase I trial in 12 patients. There were significant improvements of IIEF and EHS in 9 out of 12 patients in combination with a PDE5i and an increasing dosage. It should be noted, however, that this study was only powered to assess safety, and it is reassuring to note that no serious adverse events were reported. Moreover, Haahr et al. (80) injected a single dose of autologous ADSC (after liposuction) in 21 patients in a single arm phase I trial. Here as well, the IIEF increased substantially after 6-7 months of follow-up (53\% of patients were able to achieve penetrative sexual intercourse without use of oral medications), and this effect was sustained even after 12 months (81). There were only minor liposuctionrelated side-effects. Schweizer et al. (82) injected ex vivo expanded MSC intravenously in 7 patients in a single-arm phase I trial, prior to RP. Subsequently, after RP, no homing 
of MSC to prostatic tissue could be detected. There were also no safety issues.

For treatment of diabetic and vasculogenic ED, Bahk et al. (83) injected umbilical-cord-derived MSCs into the corpora cavernosa of 7 patients; they reported improved erectile function in 6 out of 7 patients (in conjunction with PDE5i) of whom 1 patient was confident enough without PDE5i. There were no serious adverse events. Al Demour et al. (84) injected two consecutive intracavernous autologous BMSC doses in four diabetic patients with refractory ED in a single-arm phase I trial. No patients reported adverse events after 2 years, and the authors reported a significant improvement in sexual function. In another study, Protogerou et al. (85) examined the use of ADSC + platelet lysate versus platelet lysate only in 8 patients with ED due to diabetes mellitus, hypertension, hypercholesterolemia, or PD. No severe adverse events were reported, except minor pain at the site of injection. Erectile function and morning erections improved after 1-3 months of follow-up.

Levy et al. $(86,87)$ injected placental matrix-derived MSCs in 5 patients with PD. In total, 10 plaques were managed, of which 7 had completely disappeared at 3-month follow-up. Moreover, there was a statistically significant increase in peak systolic velocity on doppler ultrasound. No significant adverse events were reported.

We can conclude from the trials discussed that many questions remain unanswered regarding SCT for ED. The presence of immunogenicity of stem cell lysates has not been fully elucidated, while the choice between autologous or allogenic injection remains uncertain. While autologous stem cells are less immunogenic, the acquisition is still laborious. The optimal passage number after ex vivo expansion and cell concentration to be injected are unclear as well. Whether the dosing should be based on patient characteristics or tissue characteristics also remains to be determined. Moreover, intracavernous injection is the most abundantly used route of administration; however, intravenous injection causes less morbidity and is less invasive and should be further examined. The timing of injection is yet unresolved, and it is unclear whether it is more desirable to use a single injection or consecutive injections.

The readily available PSC and USC (and their cultured media) can represent a valuable alternative for ADSC and BMSC, as their commercial biobanking and standardization of research protocols might aid in future investigational efforts. Lastly, the large majority of studies discussed had a single-arm design in a phase I trial of low number and were not powered sufficiently to assess any potential beneficial effect. We do know, however, that these injections appear to be safe and mostly cause only minor discomfort on the injection site. Future studies should focus on a robust, placebo-controlled double-blind randomized design, and only then will we be able to assess the true efficacy of stem cells for various disease-related refractory ED.

\section{Conclusions}

A significant number of preliminary trials have been conducted in order to investigate the various regenerative therapies of ED. While on the surface these approaches seem promising, the data is not conclusive enough to recommend any regenerative medicine techniques in urology. At the present time, patients should not be offered these therapies unless as part of a well-designed clinical trial (14). Additional RCTs with adequate controls, long follow-up periods, standardized protocols, and translatable patient populations are essential before any of these therapies can be part of our daily armamentarium.

\section{Acknowledgments}

Funding: None.

\section{Footnote}

Provenance and Peer Review: This article was commissioned by the Guest Editors (Larry I. Lipshultz, Alexander W. Pastuszak) for the focused issue "Contemporary Issues and Controversies in Men's Health" published in Translational Andrology and Urology. The article was sent for external peer review organized by the Guest Editors and the editorial office.

Conflicts of Interest: The focused issue "Contemporary Issues and Controversies in Men's Health" was commissioned by the editorial office without any funding or sponsorship. The authors have no conflicts of interest to declare.

Ethical Statement: The authors are accountable for all aspects of the work in ensuring that questions related to the accuracy or integrity of any part of the work are appropriately investigated and resolved.

Open Access Statement: This is an Open Access article distributed in accordance with the Creative Commons 
Attribution-NonCommercial-NoDerivs 4.0 International License (CC BY-NC-ND 4.0), which permits the noncommercial replication and distribution of the article with the strict proviso that no changes or edits are made and the original work is properly cited (including links to both the formal publication through the relevant DOI and the license). See: https://creativecommons.org/licenses/by-ncnd/4.0/.

\section{References}

1. Ayta IA, McKinlay JB, Krane RJ. The likely worldwide increase in erectile dysfunction between 1995 and 2025 and some possible policy consequences. BJU Int 1999;84:50-6.

2. Corona G, Lee DM, Forti G, et al. Age-related changes in general and sexual health in middle-aged and older men: results from the European Male Ageing Study (EMAS). J Sex Med 2010;7:1362-80.

3. Wessells H, Joyce GF, Wise M, et al. Erectile dysfunction. J Urol 2007;177:1675-81.

4. Burnett AL, Nehra A, Breau RH, et al. Erectile Dysfunction: AUA Guideline. J Urol 2018;200:633-41.

5. Bella AJ, Lee JC, Carrier S, et al. 2015 CUA Practice guidelines for erectile dysfunction. Can Urol Assoc J 2015;9:23-9.

6. Jannini EA, Isidori AM, Gravina GL, et al. The ENDOTRIAL study: a spontaneous, open-label, randomized, multicenter, crossover study on the efficacy of sildenafil, tadalafil, and vardenafil in the treatment of erectile dysfunction. J Sex Med 2009;6:2547-60.

7. Balhara YP, Sarkar S, Gupta R. Phosphodiesterase-5 inhibitors for erectile dysfunction in patients with diabetes mellitus: A systematic review and meta-analysis of randomized controlled trials. Indian J Endocrinol Metab 2015;19:451-61.

8. Limoncin E, Gravina GL, Corona G, et al. Erectile function recovery in men treated with phosphodiesterase type 5 inhibitor administration after bilateral nerve-sparing radical prostatectomy: a systematic review of placebocontrolled randomized trials with trial sequential analysis. Andrology 2017;5:863-72.

9. Mulhall JP, Brock G, Oelke M, et al. Effects of Tadalafil Once-Daily or On-Demand vs Placebo on Return to Baseline Erectile Function After Bilateral Nerve-Sparing Radical Prostatectomy--Results from a Randomized Controlled Trial (REACTT). J Sex Med 2016;13:679-83. 10. Lakin MM, Montague DK, VanderBrug Medendorp S, et al. Intracavernous injection therapy: analysis of results and complications. J Urol 1990;143:1138-41.

11. Burnett AL, Nehra A, Breau RH, et al. Erectile Dysfunction: AUA Guideline. J Urol 2018;200:633-41.

12. Campbell JD, Milenkovic $U$, Albersen $M$, et al. What is the Future of Erectile Dysfunction Therapy? Curr Sex Health Rep 2018;10:169.

13. Milenkovic U, Campbell J, Roussel E, et al. An update on emerging drugs for the treatment of erectile dysfunction. Expert Opin Emerg Drugs 2018;23:319-30.

14. SMSNA Position Statement on Restorative Therapies for ED. Available online: http://www.smsna.org/V1/news/433smsna-position-statement-on-restorative-therapies-fored2018

15. Sampson S, Gerhardt M, Mandelbaum B. Platelet rich plasma injection grafts for musculoskeletal injuries: a review. Curr Rev Musculoskelet Med 2008;1:165-74.

16. Scott S, Roberts M, Chung E. Platelet-Rich Plasma and Treatment of Erectile Dysfunction: Critical Review of Literature and Global Trends in Platelet-Rich Plasma Clinics. Sex Med Rev 2019;7:306-12.

17. Matz EL, Pearlman AM, Terlecki RP. Safety and feasibility of platelet rich fibrin matrix injections for treatment of common urologic conditions. Investig Clin Urol 2018;59:61-5.

18. Epifanova MV, Chalyi ME, Krasnov AO. Investigation of mechanisms of action of growth factors of autologous platelet-rich plasma used to treat erectile dysfunction. Urologiia 2017;(4):46-8.

19. Epifanova MV, Gvasalia BR, Durashov MA, et al. PlateletRich Plasma Therapy for Male Sexual Dysfunction: Myth or Reality? Sex Med Rev 2020;8:106-13.

20. Campbell JD, Burnett AL. Neuroprotective and Nerve Regenerative Approaches for Treatment of Erectile Dysfunction after Cavernous Nerve Injury. Int J Mol Sci 2017. doi: 10.3390/ijms18081794.

21. Chen KC, Minor TX, Rahman NU, et al. The additive erectile recovery effect of brain-derived neurotrophic factor combined with vascular endothelial growth factor in a rat model of neurogenic impotence. BJU Int 2005;95:1077-80.

22. Musicki B, Palese MA, Crone JK, et al. Phosphorylated endothelial nitric oxide synthase mediates vascular endothelial growth factor-induced penile erection. Biol Reprod 2004;70:282-9.

23. Ding XG, Li SW, Zheng XM, et al. The effect of plateletrich plasma on cavernous nerve regeneration in a rat model. Asian J Androl 2009;11:215-21. 
24. Wu CC, Wu YN, Ho HO, et al. The neuroprotective effect of platelet-rich plasma on erectile function in bilateral cavernous nerve injury rat model. J Sex Med 2012;9:2838-48.

25. Wu YN, Wu CC, Sheu MT, et al. Optimization of platelet-rich plasma and its effects on the recovery of erectile function after bilateral cavernous nerve injury in a rat model. J Tissue Eng Regen Med 2016;10:E294-304.

26. Dhurat R, Sukesh M. Principles and Methods of Preparation of Platelet-Rich Plasma: A Review and Author's Perspective. J Cutan Aesthet Surg 2014;7:189-97.

27. Sadeghi-Ataabadi M, Mostafavi-Pour Z, Vojdani Z, et al. Fabrication and characterization of platelet-rich plasma scaffolds for tissue engineering applications. Mater Sci Eng C Mater Biol Appl 2017;71:372-80.

28. Anitua E, Muruzabal F, de la Fuente M, et al. Plasma Rich in Growth Factors for the Treatment of Ocular Surface Diseases. Curr Eye Res 2016;41:875-82.

29. Patel AN, Selzman CH, Kumpati GS, et al. Evaluation of autologous platelet rich plasma for cardiac surgery: outcome analysis of 2000 patients. J Cardiothorac Surg 2016;11:62.

30. Lei J, Priddy LB, Lim JJ, et al. Identification of Extracellular Matrix Components and Biological Factors in Micronized Dehydrated Human Amnion/ Chorion Membrane. Adv Wound Care (New Rochelle) 2017;6:43-53.

31. Oottamasathien S, Hotaling JM, Craig JR, et al. Amniotic therapeutic biomaterials in urology: current and future applications. Transl Androl Urol 2017;6:943-50.

32. Patel VR, Samavedi S, Bates AS, et al. Dehydrated Human Amnion/Chorion Membrane Allograft Nerve Wrap Around the Prostatic Neurovascular Bundle Accelerates Early Return to Continence and Potency Following Robot-assisted Radical Prostatectomy: Propensity Scorematched Analysis. Eur Urol 2015;67:977-80.

33. Ogaya-Pinies G, Palayapalam-Ganapathi H, Rogers T, et al. Can dehydrated human amnion/chorion membrane accelerate the return to potency after a nerve-sparing robotic-assisted radical prostatectomy? Propensity scorematched analysis. J Robot Surg 2018;12:235-43.

34. Zou ZJ, Liang JY, Liu ZH, et al. Low-intensity extracorporeal shock wave therapy for erectile dysfunction after radical prostatectomy: a review of preclinical studies. Int J Impot Res 2018;30:1-7.

35. Chung E, Wang J. A state-of-art review of low intensity extracorporeal shock wave therapy and lithotripter machines for the treatment of erectile dysfunction. Expert
Rev Med Devices 2017;14:929-34.

36. Qiu X, Lin G, Xin Z, et al. Effects of low-energy shockwave therapy on the erectile function and tissue of a diabetic rat model. J Sex Med 2013;10:738-46.

37. Fode M, Hatzichristodoulou G, Serefoglu EC, et al. Lowintensity shockwave therapy for erectile dysfunction: is the evidence strong enough? Nat Rev Urol 2017;14:593-606.

38. Assaly-Kaddoum R, Giuliano F, Laurin M, et al. Low Intensity Extracorporeal Shock Wave Therapy Improves Erectile Function in a Model of Type II Diabetes Independently of NO/cGMP Pathway. J Urol 2016;196:950-6.

39. Lei H, Xin H, Guan R, et al. Low-intensity Pulsed Ultrasound Improves Erectile Function in Streptozotocin-induced Type I Diabetic Rats. Urology 2015;86:1241.e11-8.

40. Li H, Matheu MP, Sun F, et al. Low-energy Shock Wave Therapy Ameliorates Erectile Dysfunction in a Pelvic Neurovascular Injuries Rat Model. J Sex Med 2016;13:22-32.

41. Jeong HC, Jeon SH, Qun ZG, et al. Effects of NextGeneration Low-Energy Extracorporeal Shockwave Therapy on Erectile Dysfunction in an Animal Model of Diabetes. World J Mens Health 2017;35:186-95.

42. Wang B, Ning $H$, Reed-Maldonado AB, et al. LowIntensity Extracorporeal Shock Wave Therapy Enhances Brain-Derived Neurotrophic Factor Expression through PERK/ATF4 Signaling Pathway. Int J Mol Sci 2017. doi: 10.3390/ijms18020433.

43. Zhu GQ, Jeon SH, Bae WJ, et al. Efficient Promotion of Autophagy and Angiogenesis Using Mesenchymal Stem Cell Therapy Enhanced by the Low-Energy Shock Waves in the Treatment of Erectile Dysfunction. Stem Cells Int 2018;2018:1302672.

44. Jeon SH, Shrestha KR, Kim RY, et al. Combination Therapy Using Human Adipose-derived Stem Cells on the Cavernous Nerve and Low-energy Shockwaves on the Corpus Cavernosum in a Rat Model of Post-prostatectomy Erectile Dysfunction. Urology 2016;88:226.e1-9.

45. Srini VS, Reddy RK, Shultz T, et al. Low intensity extracorporeal shockwave therapy for erectile dysfunction: a study in an Indian population. Can J Urol 2015;22:7614-22.

46. Vardi Y, Appel B, Kilchevsky A, et al. Does low intensity extracorporeal shock wave therapy have a physiological effect on erectile function? Short-term results of a randomized, double-blind, sham controlled study. J Urol 2012;187:1769-75. 
47. Yee CH, Chan ES, Hou SS, et al. Extracorporeal shockwave therapy in the treatment of erectile dysfunction: a prospective, randomized, double-blinded, placebo controlled study. Int J Urol 2014;21:1041-5.

48. Kalyvianakis D, Hatzichristou D. Low-Intensity Shockwave Therapy Improves Hemodynamic Parameters in Patients With Vasculogenic Erectile Dysfunction: A Triplex Ultrasonography-Based Sham-Controlled Trial. J Sex Med 2017;14:891-7.

49. Kitrey ND, Gruenwald I, Appel B, et al. Penile Low Intensity Shock Wave Treatment is Able to Shift PDE5i Nonresponders to Responders: A Double-Blind, Sham Controlled Study. J Urol 2016;195:1550-5.

50. Fojecki GL, Tiessen S, Osther PJ. Extracorporeal shock wave therapy (ESWT) in urology: a systematic review of outcome in Peyronie's disease, erectile dysfunction and chronic pelvic pain. World J Urol 2017;35:1-9.

51. Palmieri A, Imbimbo C, Creta $M$, et al. Tadalafil once daily and extracorporeal shock wave therapy in the management of patients with Peyronie's disease and erectile dysfunction: results from a prospective randomized trial. Int J Androl 2012;35:190-5.

52. Campbell JD, Trock BJ, Oppenheim AR, et al. Metaanalysis of randomized controlled trials that assess the efficacy of low-intensity shockwave therapy for the treatment of erectile dysfunction. Ther Adv Urol 2019;11:1756287219838364.

53. Clavijo RI, Kohn TP, Kohn JR, et al. Effects of LowIntensity Extracorporeal Shockwave Therapy on Erectile Dysfunction: A Systematic Review and Meta-Analysis. J Sex Med 2017;14:27-35.

54. Lu Z, Lin G, Reed-Maldonado A, et al. Low-intensity Extracorporeal Shock Wave Treatment Improves Erectile Function: A Systematic Review and Meta-analysis. Eur Urol 2017;71:223-33.

55. Man L, Li G. Low-Intensity Extracorporeal Shock Wave Therapy for Erectile Dysfunction: a Systematic Review and Meta-Analysis. Urology 2018;119:97-103.

56. Zou ZJ, Tang LY, Liu ZH, et al. Short-term efficacy and safety of low-intensity extracorporeal shock wave therapy in erectile dysfunction: a systematic review and metaanalysis. Int Braz J Urol 2017;43:805-21.

57. Vardi Y, Appel B, Jacob G, et al. Can low-intensity extracorporeal shockwave therapy improve erectile function? A 6-month follow-up pilot study in patients with organic erectile dysfunction. Eur Urol 2010;58:243-8.

58. Tsai CC, Wang CJ, Lee YC, et al. Low-Intensity Extracorporeal Shockwave Therapy Can Improve
Erectile Function in Patients Who Failed to Respond to Phosphodiesterase Type 5 Inhibitors. Am J Mens Health 2017;11:1781-90.

59. Hisasue S, China T, Horiuchi A, et al. Impact of aging and comorbidity on the efficacy of low-intensity shock wave therapy for erectile dysfunction. Int J Urol 2016;23:80-4.

60. Fojecki GL, Tiessen S, Osther PJ. Effect of Low-Energy Linear Shockwave Therapy on Erectile Dysfunction-A Double-Blinded, Sham-Controlled, Randomized Clinical Trial. J Sex Med 2017;14:106-12.

61. Fojecki GL, Tiessen S, Osther PJS. Effect of Linear LowIntensity Extracorporeal Shockwave Therapy for Erectile Dysfunction-12-Month Follow-Up of a Randomized, Double-Blinded, Sham-Controlled Study. Sex Med 2018;6:1-7.

62. Olsen AB, Persiani M, Boie S, et al. Can low-intensity extracorporeal shockwave therapy improve erectile dysfunction? A prospective, randomized, double-blind, placebo-controlled study. Scand J Urol 2015;49:329-33.

63. Yamaçake KGR, Carneiro F, Cury J, et al. Low-intensity shockwave therapy for erectile dysfunction in kidney transplant recipients. A prospective, randomized, double blinded, sham-controlled study with evaluation by penile Doppler ultrasonography. Int J Impot Res 2019;31:195-203.

64. Hanson-Divers C, Jackson SE, Lue TF, et al. Health outcomes variables important to patients in the treatment of erectile dysfunction. J Urol 1998;159:1541-7.

65. Soebadi MA, Milenkovic U, Weyne E, et al. Stem Cells in Male Sexual Dysfunction: Are We Getting Somewhere? Sex Med Rev 2017;5:222-35.

66. Oliveira MS, Barreto-Filho JB. Placental-derived stem cells: Culture, differentiation and challenges. World J Stem Cells 2015;7:769-75.

67. Bianco P, Robey PG, Simmons PJ. Mesenchymal stem cells: revisiting history, concepts, and assays. Cell Stem Cell 2008;2:313-9.

68. Caplan AI. MSCs: The Sentinel and Safe-Guards of Injury. J Cell Physiol 2016;231:1413-6.

69. Caplan AI, Correa D. The MSC: an injury drugstore. Cell Stem Cell 2011;9:11-15.

70. Ankrum JA, Ong JF, Karp JM. Mesenchymal stem cells: immune evasive, not immune privileged. Nat Biotechnol 2014;32:252-60.

71. Shi Y, Su J, Roberts AI, et al. How mesenchymal stem cells interact with tissue immune responses. Trends Immunol 2012;33:136-43.

72. Mangir N, Akbal C, Tarcan T, et al. Mesenchymal stem cell therapy in treatment of erectile dysfunction: 
autologous or allogeneic cell sources? Int J Urol 2014;21:1280-5.

73. Matz EL, Terlecki R, Zhang Y, et al. Stem Cell Therapy for Erectile Dysfunction. Sex Med Rev 2019;7:321-8.

74. Enver T, Pera M, Peterson C, et al. Stem cell states, fates, and the rules of attraction. Cell Stem Cell 2009;4:387-97.

75. Inaba M, Yamashita YM. Asymmetric stem cell division: precision for robustness. Cell Stem Cell 2012;11:461-9.

76. Sorrell JM, Caplan AI. Topical delivery of mesenchymal stem cells and their function in wounds. Stem Cell Res Ther 2010;1:30.

77. Jayaraman P, Nathan P, Vasanthan P, et al. Stem cells conditioned medium: a new approach to skin wound healing management. Cell Biol Int 2013;37:1122-8.

78. Lee MJ, Kim J, Lee KI, et al. Enhancement of wound healing by secretory factors of endothelial precursor cells derived from human embryonic stem cells. Cytotherapy. 2011;13:165-178.

79. Yiou R, Hamidou L, Birebent B, et al. Safety of Intracavernous Bone Marrow-Mononuclear Cells for Postradical Prostatectomy Erectile Dysfunction: An Open Dose-Escalation Pilot Study. Eur Urol 2016;69:988-91.

80. Haahr MK, Jensen CH, Toyserkani NM, et al. Safety and Potential Effect of a Single Intracavernous Injection of Autologous Adipose-Derived Regenerative Cells in Patients with Erectile Dysfunction Following Radical Prostatectomy: An Open-Label Phase I Clinical Trial. EBioMedicine 2016;5:204-10.

81. Haahr MK, Harken Jensen C, Toyserkani NM, et al. A 12-Month Follow-up After a Single Intracavernous

Cite this article as: Campbell JD, Milenkovic U, Usta MF, Albersen M, Bivalacqua TJ. The good, bad, and the ugly of regenerative therapies for erectile dysfunction. Transl Androl Urol 2020;9(Suppl 2):S252-S261. doi: 10.21037/tau.2019.10.06
Injection of Autologous Adipose-Derived Regenerative Cells in Patients with Erectile Dysfunction Following Radical Prostatectomy: An Open-Label Phase I Clinical Trial. Urology 2018;121:203.e6-13.

82. Schweizer MT, Wang H, Bivalacqua TJ, et al. A Phase I Study to Assess the Safety and Cancer-Homing Ability of Allogeneic Bone Marrow-Derived Mesenchymal Stem Cells in Men with Localized Prostate Cancer. Stem Cells Transl Med 2019;8:441-9.

83. Bahk JY, Jung JH, Han H, et al. Treatment of diabetic impotence with umbilical cord blood stem cell intracavernosal transplant: preliminary report of 7 cases. Exp Clin Transplant 2010;8:150-60.

84. Al Demour S, Jafar H, Adwan S, et al. Safety and Potential Therapeutic Effect of Two Intracavernous Autologous Bone Marrow Derived Mesenchymal Stem Cells injections in Diabetic Patients with Erectile Dysfunction: An Open Label Phase I Clinical Trial. Urol Int 2018;101:358-65.

85. Protogerou V, Michalopoulos E, Mallis P, et al. Administration of Adipose Derived Mesenchymal Stem Cells and Platelet Lysate in Erectile Dysfunction: A Single Center Pilot Study. Bioengineering (Basel) 2019. doi: 10.3390/bioengineering6010021.

86. Levy JA, Marchand M, Iorio L, et al. Determining the Feasibility of Managing Erectile Dysfunction in Humans With Placental-Derived Stem Cells. J Am Osteopath Assoc 2016;116:e1-5.

87. Levy JA, Marchand M, Iorio L, et al. Effects of Stem Cell Treatment in Human Patients With Peyronie Disease. J Am Osteopath Assoc 2015;115:e8-13. 